\title{
EVALUATING THE ACCURACY OF POST-PROCESSED KINEMATIC (PPK) POSITIONING TECHNIQUE
}

\author{
Atinç PIRTI (1D ${ }^{*}$ \\ Department of Surveying Engineering, Yildiz Technical University, Davutpasa Campus, \\ 34322-Esenler, Istanbul, Turkey
}

Received 14 March 2020; accepted 14 June 2021

\begin{abstract}
Post-processing kinematics (PPK) is positioning process in which signals received from a mobile receiving device store location data can be adjusted using corrections from a reference station after data has been collected. The processed kinematic screening method provides the surveyor with a technique for high production survey measurements and can be used in areas with minimal satellite barriers. PPK uses significantly reduced observation times compared to static or fast static observations. This method requires least squares adjustment or another multiple basic statistical analysis that can produce a weighted average of observations. The results obtained using PPK are between $1 \mathrm{~cm}$ and $3 \mathrm{~cm}$ for horizontal coordinates and from $1 \mathrm{~cm}$ to $10 \mathrm{~cm}$ for vertical coordinates.
\end{abstract}

Keywords: post-processed kinematic, accuracy, positioning, evaluation, total station, precision.

\section{Introduction}

In many research areas, speed and efficiency are the key to success. Kinematics is the most effective way of working on a satellite. It uses relativistic positioning techniques with carrier phase observations. These surveys can provide snapshots to the point coordinates when the receiver is still in place or on the go. It's usually less accurate than what is obtained through static, but most are sufficient for survey form. It has applications in many fields of research, such as mapping, border, construction, and photogrammetry. The kinematic measurement can provide immediate results using real-time kinematic (RTK) mode or using post-process kinematic (PPK) mode in the office. For example, kinematic works have been successfully used to locate drilling ships during hydrographic studies and to position aerial cameras during photogrammetric work. Used to guide machine controlled digging in large construction projects. Useful for non-research applications such as high precision agriculture. The main difference between static and kinematic measurement techniques is time per session. Creating control points using the static method requires much longer sessions than those used in kinematics (El-Shouny et al., 2017; Wolf \& Ghilani, 2008; El-Rabbany, 2006; Landau et al., 2002; Pirti, 2007, 2008; Pirti et al., 2009; Hoffmann-Wellenhof et al., 2008).
Data collected on post-processing kinematic (PPK) work is stored in the survey controller or recipient until the field work is completed. The data is then processed in the office using the same software and processing techniques used in static surveys. Data latency in PPK surveys is not a problem because the data is then processed. The other benefits of PPK research are that sensitive ephemeris can be combined with observational data removal failures in their publication ephemeris, and the base station coordinates can be resolved after the field is completed. Therefore, the coordinates of the base station must not be known before the survey. Data latency and a precise ephemeris have led to a slight improvement in PPK, slightly higher than RTK. RTK's research, as the implication, allows for instant detection of scores during a study at a travel point. The advantages of RTK's surveys have been its ability to reduce office time and verify surveillance in the field. When using RTK, the data can be immediately downloaded to a GIS or to an existing measurement project. This increases the overall productivity of the survey (El-Shouny et al., 2017).

- Five or more satellites must be observed.

- Buyers must be initiated according to the manufacturer's recommendations.

- Unless data is collected on the move, each point must be in a different session with different satellite ge-

${ }^{*}$ Corresponding author. E-mail: atinc@yildiz.edu.tr 
ometry, e.g. during Light Detection and Exchange (LiDAR).

- Recording speed must be between one and five seconds.

- Although dual-frequency receivers are preferred, single-frequency receivers can be used (Wolf \& Ghilani, 2008).

\section{Methodology}

The study was done in Afyon, Turkey. Tests were conducted to evaluate the PPK method's performance in the project area. The purpose of all tests was to evaluate the achievable accuracy of the PPK in the project and check the results. In these tests, the accuracy assessment of PPK was performed by comparing the coordinates of a group of points determined separately from a series of PPK tests. For this purpose, two reference points (N1 and N2) in the project area (Dinar region of Afyon, see Figure 1). A static GNSS survey was carried out to determine the coordinates of two reference points ( $\mathrm{N} 1$ and N2) in the project area. N1 and N2 points control points were taken for terrestrial measurements. N1 and N2 coordinates were calculated in static GNSS observations (6 hours) by fixing four CORS-TR reference points (AFYN, DENI, DINA and ISPT). The minimum height cutting angle and sampling rate were $10 \mathrm{o}$ and 30 seconds. All measurements were performed using Ashtech Pro-Mark 800 GNSS receivers. Data processing (Precision ephemerides are used) and network adjustments were made using Topcon Link v.8.2.3. In the adjustment procedure, ITRF 2005 coordinates of the four

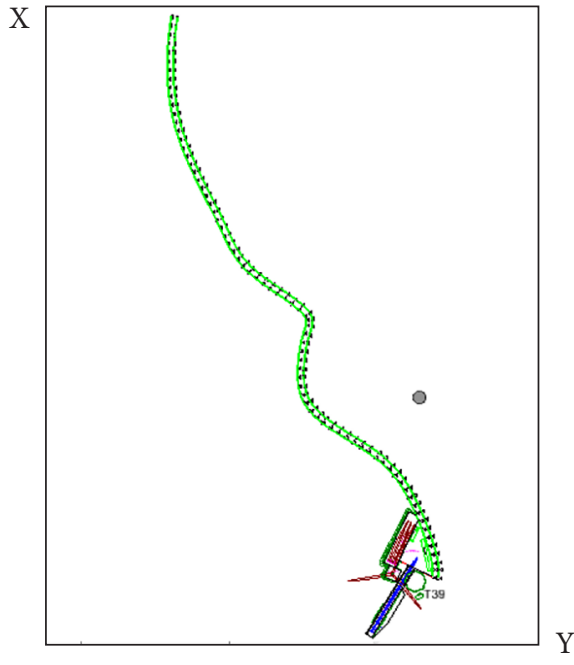

Figure 2. Project area in Afyon

CORS-TR points (AFYN, DENI, DINA and ISPT) are fixed (Table 1). The CORS-TR station DINA was about $4 \mathrm{~km}$ away from the project site, see Figure 1.

The hundred points marked in the project area was included in the study. Figure 2 shows the distribution of the points tested. Horizontal angle, zenith angle and horizontal distance were surveyed using two points (N1 and N2) with Sokkia Set320 (Angle accuracy: 2", Distance measurement accuracy: $2 \mathrm{~mm}+2 \mathrm{ppm}$ ) to calculate the coordinates of 100 points.

In these tests, GNSS equipment was used with PPK test consisting of Ashtech Pro-Mark 800 GNSS receiver
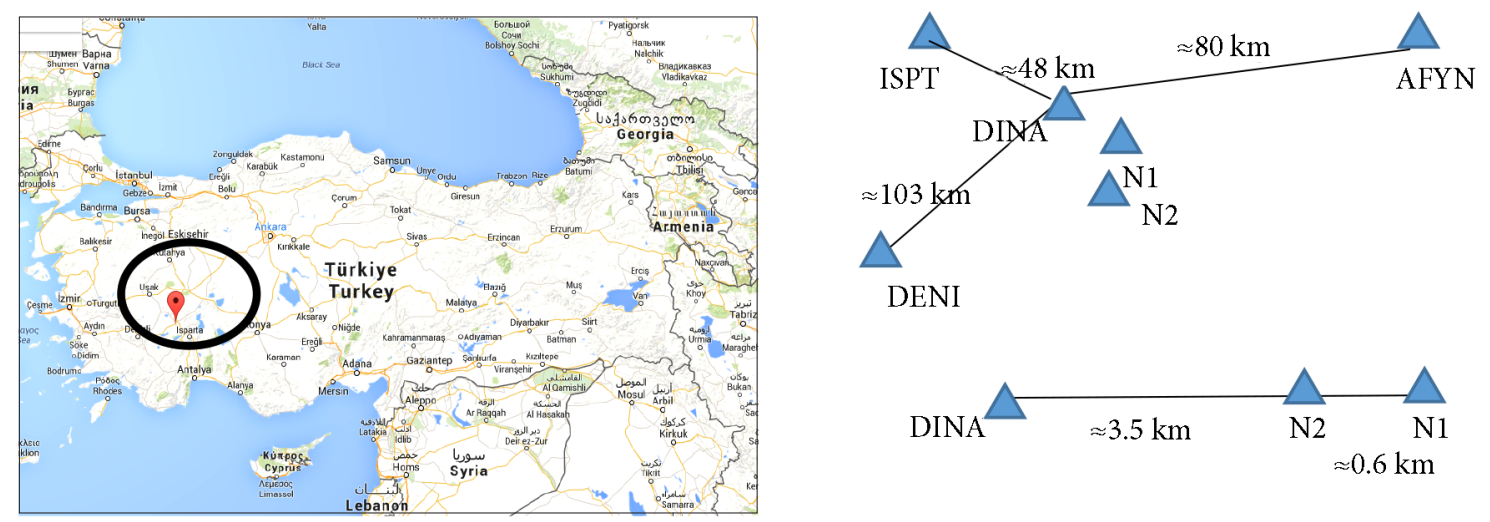

Figure 1. Project area and GNSS network

Table 1. The coordinates and standard deviations of the N1, N2 and CORS-TR reference points

\begin{tabular}{|c|c|c|c|c|c|c|}
\hline Points & Northing $(\mathrm{m})$ & Easting $(\mathrm{m})$ & $\mathrm{Up}(\mathrm{m})$ & Std $(\mathrm{N})[\mathrm{mm}]$ & Std $(\mathrm{E})[\mathrm{mm}]$ & Std $(\mathrm{U})[\mathrm{mm}]$ \\
\hline AFYN & 4289608.921 & 548776.840 & 1072.453 & 0 & 0 & 0 \\
\hline DENI & 4181481.507 & 420002.663 & 471.264 & 0 & 0 & 0 \\
\hline DINA & 4215222.037 & 514596.418 & 918.071 & 0 & 0 & 0 \\
\hline ISPT & 4183796.260 & 549944.753 & 1032.314 & 0 & 3 & 0 \\
\hline N1 & 4217705.182 & 516510.023 & 1105.739 & 3 & 3 & 6 \\
\hline N2 & 4217204.029 & 516749.932 & 1098.980 & 3 & 3 & 6 \\
\hline
\end{tabular}


(Kinematic (Horizontal accuracy $0.010 \mathrm{~m}+1.0 \mathrm{ppm}$, Vertical accuracy $0.020 \mathrm{~m}+1 \mathrm{ppm})$ ). Data acquisition and processing speed is set to one second with a 10 degree cutting mask angle. Ten measurement epochs were performed for each station and the average of the ten epochs was recorded while examining the coordinates. Independent CORS-TR (VRS-FKP) tests covering all test points were performed using methods (VRS-FKP) to evaluate PPK accuracy. The tests were carried out at different times of the three days (VRS-FKP). Table 2 shows the methods, dates, times, and observations. The number of satellites observed varied between 8-13 (GPS + GLONASS) satellites and the PDOP average values were recorded for all tests between 1.2 and 2.5 (El-Rabbany, 2006).

Table 2. Time schedule of the CORS measurements by using two (VRS/FKP) methods

\begin{tabular}{|l|l|l|}
\hline \multicolumn{1}{|c|}{ Method } & \multicolumn{1}{|c|}{ Date } & \multicolumn{1}{|c|}{ Time Interval $(\mathrm{h})$} \\
\hline VRS & $10,11,12^{\text {th }}$ October & $\begin{array}{l}9: 00-11: 00 ; 13: 30-15: 30 ; \\
16: 00-18: 00\end{array}$ \\
\hline FKP & $\begin{array}{l}23,25,28^{\text {th }} \text { October } \\
\text { 9:00-11:00; 13:30-15:30; } \\
16: 00-18: 05\end{array}$ \\
\hline
\end{tabular}

\section{Results of the experiments}

\subsection{Experiment 1: The results of VRS, FKP and PPK}

The aim of the experiment was to check the PPK performance in the project environment. First of all, the study was carried out using PPK on October 9, 2019. Figure 3 shows the coordinate differences between FKP (23.10.2013) and PPK survey results. Figure 3 also shows the mean and standard deviation values of the coordinate differences. The mean differences between the PPK and FKP (23.10.2013) survey were less than $3 \mathrm{~cm}$ for the horizontal components and less than $3 \mathrm{~cm}$ along the vertical components. The standard deviation of the horizontal coordinate differences was about $3 \mathrm{~cm}$ for the study areas. The standard deviation of the height differences was about $3 \mathrm{~cm}$ for the project areas (see Figure 3 ). The variations in horizontal and vertical components were recorded for the hundred points (the project area) (see Figure 3 ). The variations were about $9 \mathrm{~cm}$ in the $\mathrm{X}-\mathrm{Y}$ coordinates and about $10 \mathrm{~cm}$ in the $\mathrm{H}$ coordinates in the study environment.

Figure 4 shows the coordinate differences between FKP (25.10.2013) and PPK survey results. Figure 4 also shows the mean and standard deviation values of the coordinate differences. The mean differences between the PPK and FKP (25.10.2013) survey were less than $3 \mathrm{~cm}$ for the horizontal components and less than $3 \mathrm{~cm}$ along the vertical components. The standard deviation of the horizontal coordinate differences was about $3 \mathrm{~cm}$ for the study areas. The standard deviation of the height differences was about $3 \mathrm{~cm}$ for the project areas (see Figure 4). The variations in horizontal and vertical components were computed for the hundred points (the project area) (see Figure 4). The variations were about $9 \mathrm{~cm}$ in the $\mathrm{X}-\mathrm{Y}$ coordinates and about $10 \mathrm{~cm}$ in the $\mathrm{H}$ coordinates in the study environment.

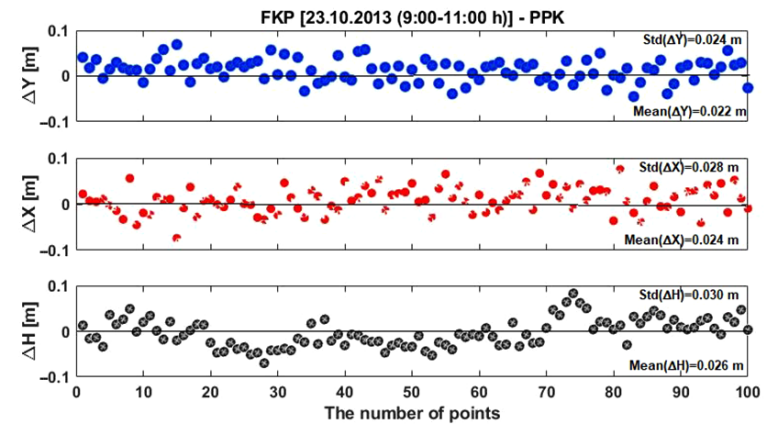

Figure 3. Comparison of the coordinates of the test points by using FKP (23.10.2013) and PPK methods

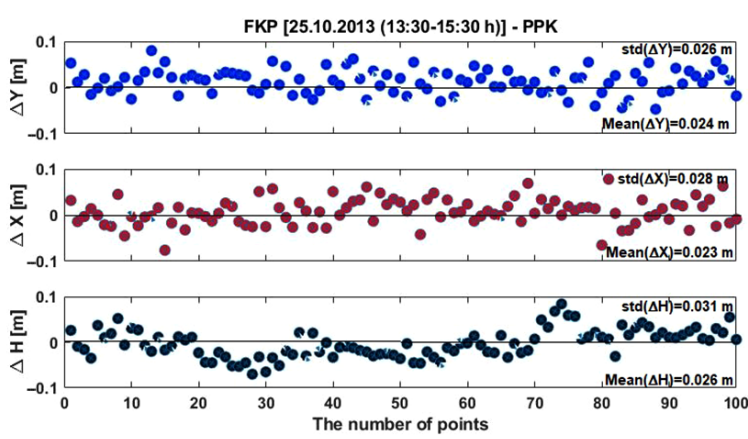

Figure 4. Comparison of the coordinates of the test points by using FKP (25.10.2013) and PPK methods

Figure 5 shows the coordinate differences between FKP (28.10.2013) and PPK survey results. Figure 5 also shows the mean and standard deviation values of the coordinate differences. The mean differences between the PPK and FKP (28.10.2013) survey were less than $3 \mathrm{~cm}$ for the horizontal components and less than $3 \mathrm{~cm}$ along the vertical components. The standard deviation of the horizontal coordinate differences was about $3 \mathrm{~cm}$ for the study areas. The standard deviation of the height differences was about $3 \mathrm{~cm}$ for the project areas (see Figure 5). The variations in horizontal and vertical components were computed for the hundred points (the project area) (see Figure 5). The variations were about $9 \mathrm{~cm}$ in the $\mathrm{X}-\mathrm{Y}$ coordinates and about $10 \mathrm{~cm}$ in the $\mathrm{H}$ coordinates in the study environment.

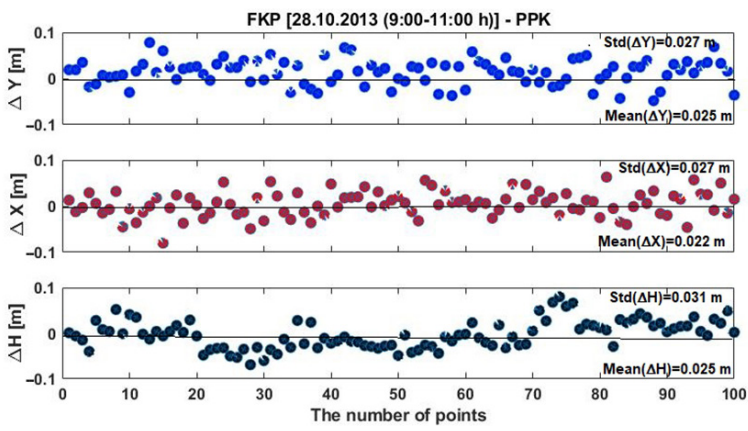

Figure 5. Comparison of the coordinates of the test points by using FKP (28.10.2013) and PPK methods 

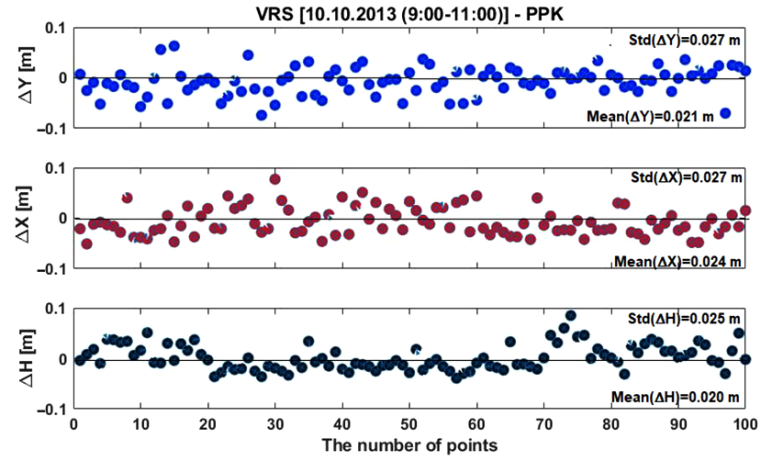

Figure 6. Comparison of the coordinates of the test points by using VRS (10.10.2013) and PPK methods

Figure 6 shows the coordinate differences between VRS (10.10.2013) and PPK survey results. Figure 6 also shows the mean and standard deviation values of the coordinate differences. The mean differences between the PPK and VRS (10.10.2013) survey were less than $3 \mathrm{~cm}$ for the horizontal components and less than $3 \mathrm{~cm}$ along the vertical components. The standard deviation of the horizontal coordinate differences was about $3 \mathrm{~cm}$ for the study areas. The standard deviation of the height differences was about $3 \mathrm{~cm}$ for the project areas (see Figure 6). The variations in horizontal and vertical components were computed for the hundred points (the project area) (see Figure 6). The variations were about $9 \mathrm{~cm}$ in the $\mathrm{X}-\mathrm{Y}$ coordinates and about $10 \mathrm{~cm}$ in the $\mathrm{H}$ coordinates in the study environment.
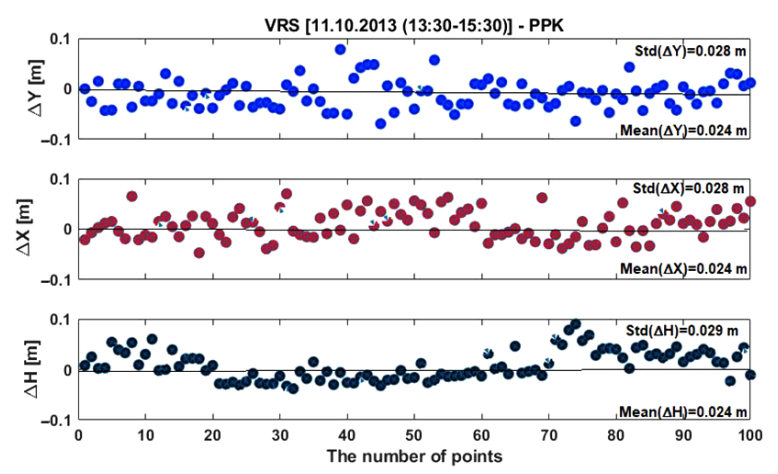

Figure 7. Comparison of the coordinates of the test points by using VRS (11.10.2013) and PPK methods

Figure 7 shows the coordinate differences between VRS (11.10.2013) and PPK survey results. Figure 7 also shows the mean and standard deviation values of the coordinate differences. The mean differences between the PPK and VRS (11.10.2013) survey were less than $3 \mathrm{~cm}$ for the horizontal components and less than $3 \mathrm{~cm}$ along the vertical components. The standard deviation of the horizontal coordinate differences was about $3 \mathrm{~cm}$ for the study areas. The standard deviation of the height differences was about $3 \mathrm{~cm}$ for the project areas (see Figure 7). The variations in horizontal and vertical components were computed for the hundred points (the project area) (see Figure 7). The variations were about $9 \mathrm{~cm}$ in the $\mathrm{X}-\mathrm{Y}$ coordinates and about $10 \mathrm{~cm}$ in the $\mathrm{H}$ coordinates in the study environment.

Figure 8 shows the coordinate differences between VRS (12.10.2013) and PPK survey results. Figure 8 also shows the mean and standard deviation values of the coordinate differences. The mean differences between the PPK and VRS (12.10.2013) survey were less than $3 \mathrm{~cm}$ for the horizontal components and less than $3 \mathrm{~cm}$ along the vertical components. The standard deviation of the horizontal coordinate differences was about $3 \mathrm{~cm}$ for the study areas. The standard deviation of the height differences was about $3 \mathrm{~cm}$ for the project areas (see Figure 8). The variations in horizontal and vertical components were computed for the hundred points (the project area) (see Figure 8). The variations were about $9 \mathrm{~cm}$ in the $\mathrm{X}-\mathrm{Y}$ coordinates and about $10 \mathrm{~cm}$ in the $\mathrm{H}$ coordinates in the study environment.
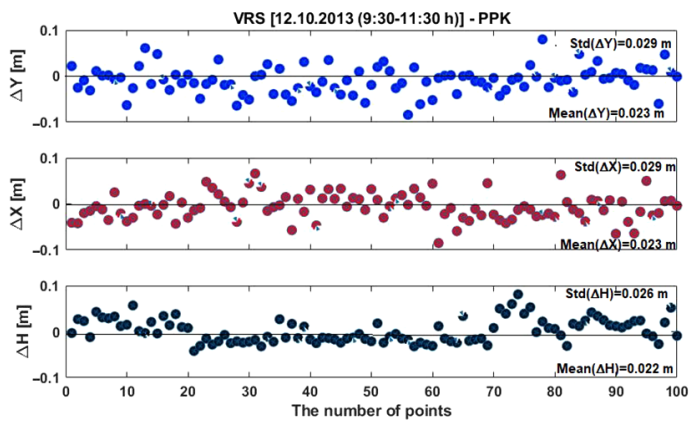

Figure 8. Comparison of the coordinates of the test points by using VRS (12.10.2013) and PPK methods

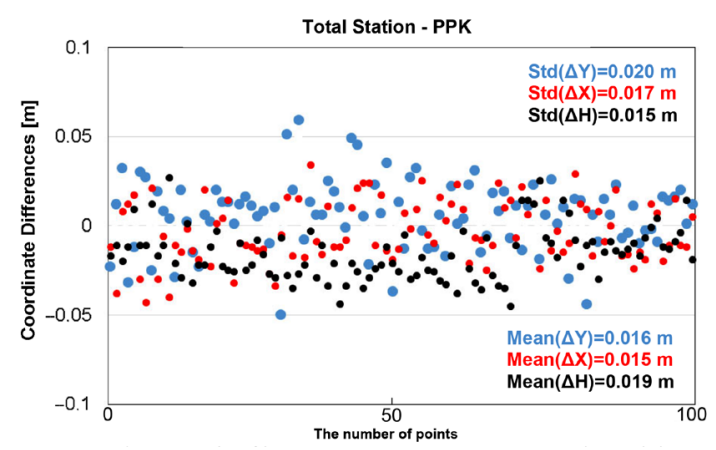

Figure 9. Comparison of the coordinates of the test points by using total station and PPK methods

Figure 9 shows the coordinate differences between the total station and PPK survey results. Figure 9 also shows the mean and standard deviation of the coordinate differences. When comparing the results of the two methods, the horizontal coordinates of the points determined by these tests appear consistent, some changes range from a few millimetres to $5-6 \mathrm{~cm}$. However, the height component was less consistent and sometimes differed between the total station and PPK surveys by up to $5 \mathrm{~cm}$ at the same points.

The comparison of the results of the PPK and total station surveys is shown in Figure 9. The standard deviation of the horizontal coordinate differences was about 
$2 \mathrm{~cm}$ for the Project areas. The standard deviation of the height differences was about $2 \mathrm{~cm}$ for the project areas (see Figure 9). As shown in Figure 9, the mean differences between the PPK survey and the total station survey were less than $2 \mathrm{~cm}$ for the horizontal components and less than $2 \mathrm{~cm}$ for the vertical components.

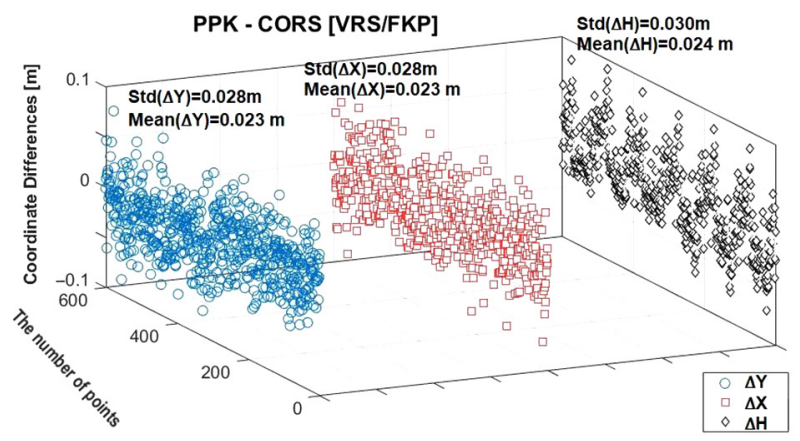

Figure 10. Compare all of the coordinates of the points by using PPK methods and CORS-TR (VRS/FKP) methods

Figure 10 shows the coordinate differences between the CORS (VRS/FKP) and PPK survey results. Figure 10 also shows the mean and standard deviation of the coordinate differences. When comparing the results of the two methods, the horizontal coordinates determined separately with these tests seem consistent, some changes from a few millimetres to $10 \mathrm{~cm}$. However, the height component was less consistent and sometimes differed between the total station and PPK surveys by up to $10 \mathrm{~cm}$ at the same points.

\section{Conclusions}

The horizontal and vertical coordinates derived from PPK were very consistent, ranging from a few millimetres to $5 \mathrm{~cm}$. At some points, the height differences at the same point between the total station and the PPK sessions were as few as a few millimetres, for others it ranged up to about 5-6 cm. At the same time, PPK has always been able to achieve $\mathrm{cm}$ level sensitivity when enough satellites are observed. The delay of the reference data did not have a significant effect on the results obtained, the effects of which are limited to a few millimetres.

This study focuses on comparative study for Cartesian $\mathrm{X}, \mathrm{Y}$ and $\mathrm{H}$ coordinates that arise between PPK and VRS/ FKP total station techniques. The results supported by statistical analysis show that the difference between PPK and VRS/FKP techniques gives the average values of $3 \mathrm{~cm}$ and $3 \mathrm{~cm}$ in the $\mathrm{X}, \mathrm{Y}$ and $\mathrm{H}$ coordinates, respectively; with standard deviation of $3 \mathrm{~cm}$, for the three Cartesian components. The above findings are considered to be insignificant in survey studies, but should be considered for precise surveys, such as monitoring of structural deformation. In addition, the use of VRS/FKP techniques has many advantages, such as the independence of the base receiver, consistent error modelling, greater productivity and limitation for radio communication.

\section{References}

El-Rabbany, A. (2006). Introduction to GPS: The global positioning system ( $2^{\text {nd }}$ ed., pp. 159-160). Artech House. https://www. amazon.com/Introduction-GPS-Global-Positioning-System/ $\mathrm{dp} / 1596930160$

El-Shouny, A., Yakoub, N., \& Hosny, M. (2017). Evaluating the performance of using PPK-GPS technique in producing topographic contour map. Marine Geodey, 40(4), 224-238. https://doi.org/10.1080/01490419.2017.1321594

Hoffmann-Wellenhof, B., Lichtenegger, H., \& Wasle, E. (2008). GNSS - Global Navigation Satellite Systems. GPS, GLONASS, Galileo, and more. Springer. https://www.springer.com/gp/book/9783211730126

Landau, H., Vollath, U., \& Chen, X. (2002). Virtual reference station systems. Journal of Global Positioning Systems, 1(2), 137-143. https://www.scirp.org/pdf/nav20090200008_97580842.pdf

Pirti, A. (2007). Performance analysis of the real time kinematic GPS (RTK GPS) technique in a highway project (stake-out). Survey Review, 39(303), 43-53. https://doi.org/10.1179/003962607X164989

Pirti, A. (2008). Evaluating the usage of RTK GPS Technique in the control of highway geometry. Geodetski List, 62(4), 237248. https://www.researchgate.net/publication/283252113_ Evaluating_the_Usage_of_RTK_GPS_Technique_in_the_ Control_of_Highway_Geometry

Pirti, A., Arslan, N., Deveci, B., Aydin, O., Erkaya, H., \& Hosbas, R. G. (2009). Real time kinematic GPS for cadastral surveying. Survey Review, 41(314), 339-351. https://doi.org/10.1179/003962609X451582

Wolf, Pr., \& Ghilani, Cd. (2008). Elementary surveying, an introduction to geomatics (12 ${ }^{\text {th }}$ ed.) Prentice Hall Upper Saddle River.

http://www.civilittee-hu.com/uploads/1/Survaying/book.pdf 